\title{
Erratum to: Migrant Children's Rights to Health and Rehabilitation: A Primer for US Social Workers
}

\author{
S. Megan Berthold ${ }^{1} \cdot$ Kathryn Libal $^{1,2}$
}

Published online: 6 July 2016

(C) Springer International Publishing 2016

Erratum to: J. Hum. Rights Soc. Work DOI 10.1007/s41134-016-0010-3

The original version of this article unfortunately contained three errors.

There were two errors on page 2 of the article: (1) The discussion of Reno v. Flores (1993) is not accurate; and (2) the ORR assumed responsibility from the INS for the care of unaccompanied migrant children in January of 2003 rather than in 2002. Therefore, the $3^{\text {rd }}$ paragraph of the section "Scope of Child Migration and Response" on page 2 of the article should start: "The responsibility for sheltering and providing for the needs of unaccompanied undocumented children in the United States has shifted over the years. Prior to the passage of the Homeland Security Act in 2002, unaccompanied children were detained in federal facilities and under the custody of the Immigration and Naturalization Service. The US Office of Refugee Resettlement (ORR) assumed responsibility from the Immigration and Naturalization Service (INS) for the care of unaccompanied migrant children in 2003. ORR receives ..." In addition, the following reference should be deleted from the reference section:

Reno v. Flores (1993). 507 U.S. 292 (1993). Retrieved from https://www.law.cornell.edu/supct/html/91-905.ZO.html The authors apologize for these errors and the inconvenience caused.
The online version of the original article can be found at http:// dx.doi.org/10.1007/s41134-016-0010-3.

S. Megan Berthold

megan.berthold@uconn.edu

1 University of Connecticut School of Social Work, 1798 Asylum Ave., West Hartford, CT 06117, USA

2 Human Rights Institute, Thomas J. Dodd Research Center, University of Connecticut, 405 Babbidge Road, U-1205, Storrs, CT 06269, USA 